\section{Y2K, Emergency Department Preparedness in New York City}

Steven Silber, DO, FACEP, ${ }^{1}$ Neill Oster, $M D ;^{2}$ Bonnie Simmons, DO, FACEP; ${ }^{3}$ Christopher Garrett, $M D^{1}$

1) Department of Emergency Medicine, New York Methodist Hospital, Brooklyn, New York USA; 2) Elmhurst Hospital Center (NO) Queens, New York USA; 3) Cabrini Medical Center, New York, New York, USA

Objectives: To study the preparedness of Emergency Departments (EDs) in New York City (NYC) for the possibilities of loss of essential services, terrorist events, and mass casualties over the $\mathrm{Y} 2 \mathrm{~K}$ weekend.

Methods: Directors of Emergency Departments of 51, 91-1-receiving hospitals in NYC were surveyed regarding staffing patterns and emergency contingencies for the New Years weekend.

Results: Forty-six (90.2\%) of the surveys were completed. All had contingencies for loss of electricity and communications. Almost all had contingencies for fuel (97.8\%), water $(97.8 \%)$, and total facility failure $(87.0 \%)$. Forty $(87.0 \%)$ instituted their disaster plan in advance of any occurrence, and 36 of those $(90.0 \%)$ planned to utilize Incident Command. Thirty-four (73.9\%) had implemented a live, mock Y2K drill. Medical (80.4\%) and nursing (87.0\%) staff also were increased and most had contingency plans for mobilizing extra personnel $(97.8 \%$ medical, $84.8 \%$ nursing). Thirty-nine (84.8\%) stated their $\mathrm{Y} 2 \mathrm{~K}$ emergency preparedness plans were influenced by the threat of terrorism.

Conclusions: The EDs in New York City were on a heightened state of alert for the $\mathrm{Y} 2 \mathrm{~K}$ weekend. This was the first full-scale disaster preparedness incident in recent history in New York City. It should be used as a basis to further improve and coordinate citywide disaster plans.

Keywords: drill, mock; emergency department; New York City; preparedness; $\mathrm{Y} 2 \mathrm{~K}$

E-mail: noster@worldnet.att.net
Predictors for People's Response to a Tornado Warning, Arkansas, 01 March, 1997

L. Balluz;, L. Schieve;, T. Holmes; S. Kiezak; J. Malilay

Centers for Disease Control and Prevention, Health

Studies Branch, Atlanta, Georgia, USA

Background: Nine powerful (F3-F4) tornadoes hit Arkansas from the southeastern to the northeastem part of the state during the afternoon of 01 March,1997. Twenty-six fatalities and 400 injured persons were reported. Little information in the public health literature has been published about people's responses to tornado warnings. To help fill this void, we assessed factors associated with people's responses to the tornado warning issued in Clark and Saline Counties, Arkansas.

Methods: We conducted a population-based, cross-sectional study. We used random digit dialing to select a sample from each of the affected counties, and we administered a comprehensive questionnaire to all selected individuals who stated they were at home prior to tornado touch down. Results: Of 146 survey participants, 140 (96\%) knew the difference between "tornado watch" and "tornado warning". Of those 140 participants, 64 (45.7\%) responded to the warning by seeking shelter, and 58 (90.6\%) of those 64 responded within five minutes of the time they became aware of the warning. Univariate and multi-variate analysis showed that factors associated with an appropriate response to the warning were educational level greater than high school $(\mathrm{OR}=4.2,95 \% \mathrm{CI}=1.1-15.5)$, having a basement in one's house $(\mathrm{OR}=3.8,95 \%$ exact $\mathrm{CI}=$ 1.1-17.1), hearing a siren $(\mathrm{OR}=4.4,95 \% \mathrm{CI}=1.3-18.9)$, and having prepared a household plan to respond when tornadoes occur $(\mathrm{OR}=2.6,95 \% \mathrm{CI}=1.1-6.3)$.

Conclusion: We recommend the following: 1) people who live in tornado-prone areas have a personal plan of action to help them respond immediately to warnings; 2 ) public health officials in tornado areas should educate the public about actions they can take to protect themselves; and 3) disaster-management officials planning protection measures, should consider the limited time people have in which to respond to a tornado warning. Thus, shelters in tornado-prone areas should be quickly accessible by residents.

Keywords: cross-sectional study; disaster response; preparedness; tornado; warnings; watches

E-mail : Lib7@cdc.gov 